\title{
AN EXPERIMENTAL STUDY OF HYDRODYNAMICS OF OWC DEVICE EMBODYING IN CAISSON BREAKWATER
}

\author{
Ching-Piao Tsai, National Chung Hsing University, cptsai@nchu.edu.tw \\ Ching-En Huang, National Chung Hsing University, j065745740@yahoo.com.tw \\ Chun-Han Ko, National Chung Hsing University, peter770417@hotmail.com \\ Ying-Chi Chen, National Chung Hsing University, taboqchi3@gmail.com
}

\section{INTRODUCTION}

It has currently become an important issue in searching for clean and sustainable renewable energy. Wave power is one of substantial renewable energies. The oscillating water column (OWC) device is the most extensively studies of wave energy converter and the largest number of prototypes so far deployed into the sea. The breakwater-integrated OWC has been constructed successfully in Sakata harbor in Japan, Mutriku port in Spain, and Civitavecchia harbor in Italy etc. The breakwater-integrated OWC has several advantages, especially much easier maintenance of the wave energy plant (Falcão and Henriques, 2016). However, the front wall of typical OWC device may be received large wave force when the storm waves impacted on it. This study proposed an improvement of a caisson type breakwater-integrated OWC device by installing a perforated front wall to reduce the wave impacting on the structure but also to promote the capture efficiency of the wave energy. This study reports the experimental results of both water and air flow characteristics inside the OWC chamber to demonstrate the hydrodynamic performance of the improved OWC device.

\section{EXPERIMENTS}

The experiments were conducted in the $15 \mathrm{~m}$ long, 50 $\mathrm{cm}$ wide and $60 \mathrm{~cm}$ deep wave flume. The flume is equipped with a piston-type regular wave generator at one end and a wave-absorber at the other end. Both sides of the flume are bounded by strengthened glass. The technique of flow visualization by means of an argon-ion laser beam ( $2.5 \mathrm{~W}, 514 \mathrm{~nm}$ for steady work) and a high speed CCD camera was employed to observe the flow characteristics of the OWC. In experiments, titanium dioxide particles and dry ice powders were evenly distributed into the water and air flow area respectively, where was illuminated by the laser sheet. The configuration of the present OWC device is shown in Figure 1.

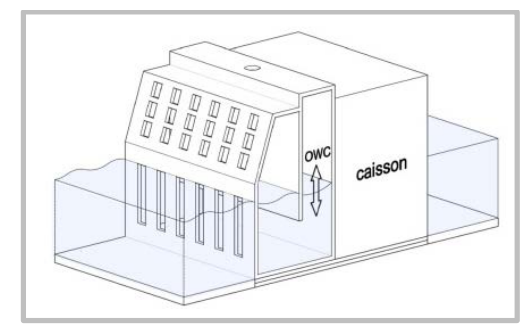

Figure 1 - Configuration of the present OWC device embodying in caisson breakwater.
RESULTS

The numerical simulations were also implemented by means of CFD software FLOW-3D by considering twofluid model to obtain the water and air flow processes induced by the oscillating water column. The FAVOR (fractional area/volumes obstacle representation) technique and the Volume of Fluid (VOF) method to track the two-fluid interfaces were employed for the numerical simulations.

Both numerical and experimental results show that the air extruding and suction processes through the orifice on the roof of the OWC chamber take place as the water level moving upward and downward. The maximum pneumatic power occurs when the mean water level of the OWC is moving upward, as shown in Figure 2.

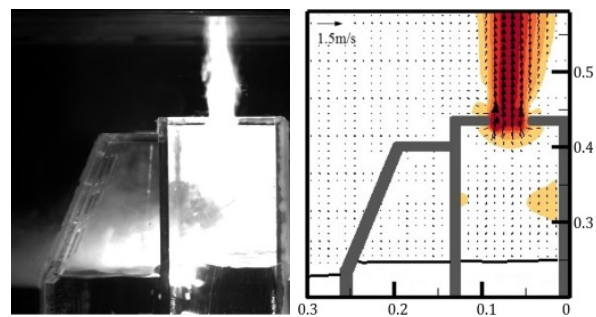

Figure 2 - Experimental and numerical results as the maximum airflow across through the orifice.

Figure 3 shows the water flow field at the instant when mean water level of OWC is moving upward and downward which enforces the water flowing through the submerged open of the OWC chamber. It can be seen that the resonant oscillating water column occurs in the present device like a U-tube. The full process of air and water flow inside the OWC chamber and the analysis of hydrodynamic performance would be presented in the conference proceedings.

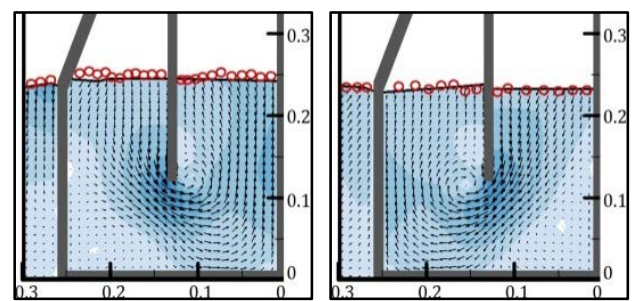

Figure 3 - Water flow field when mean water level of OWC is moving upward and downward.

\section{REFERENCES}

Falcão, Henriques (2015): Oscillating-water-column wave energy converters and air turbines: a review, Renew Energy, vol.85, pp. 391-424. 